\title{
Características Psicométricas da Versão Portuguesa da Escala de Socialização Parental na Adolescência ESPA-29
}

\author{
Psychometric Properties of the Portuguese Version of the Parental \\ Socialization Scale in Adolescence (ESPA-29)
}

\author{
Cristina Nunes ${ }^{*}, a$, Karina Luís ${ }^{a}$, Ida Lemos ${ }^{a} \&$ Gonzalo Musitu Ochoa ${ }^{b}$ \\ ${ }^{a}$ Centro de Investigação sobre Espaço e Organizações da Universidade do Algarve, Faro, Portugal \\ $\&{ }^{b}$ Universidad Pablo de Olavide, Sevilla, España
}

\begin{abstract}
Resumo
O objetivo do estudo foi validar a versão portuguesa da Escala de Estilos de Socialização Parental na Adolescência (ESPA-29) de Musitu e García (2001, 2004). Participaram 849 adolescentes de ambos os sexos (57,2\% raparigas e $42,8 \%$ rapazes), com idades compreendidas entre os 10 e os 18 anos ( $M$ $=14,57, D P=2,43)$ e residentes no sul de Portugal. A validade de constructo foi estudada através da análise fatorial exploratória e a fidelidade do instrumento através da análise da consistência interna e da estabilidade temporal (pelo método de teste-reteste). Os resultados obtidos foram consistentes com os da versão original e reproduziram a estrutura bidimensional da escala. A versão portuguesa da ESPA-29 apresentou boas características psicométricas, com níveis de consistência interna e de estabilidade temporal bastante satisfatórias. Estes resultados sugerem que a versão portuguesa da ESPA-29 é fiável para o estudo dos estilos de socialização parental em adolescentes portugueses. Palavras-chave: Estilos de socialização parental, ESPA-29, adolescência, estudo de validação.

Abstract

The aim of this study was to validate the Portuguese version of the Parental Socialization Scale in Adolescence (ESPA-29) by Musitu and García (2001, 2004). A sample of 849 adolescents $(57.2 \%$ girls and $42.8 \%$ boys), aged 10 to 18 years $(M=14.57, S D=2.43)$, from the southern region of Portugal, participated in the study. Construct validity was studied using exploratory factor analysis, and the reliability study was conducted through the analysis of internal consistency and temporal stability (through the test-retest method). Results were consistent with those obtained in the original version of the instrument and reproduced the bi-dimensional structure of the scale. Furthermore, the Portuguese version of ESPA-29 showed good psychometric characteristics, with satisfactory levels of internal consistency and temporal stability. These results suggest that this is a reliable instrument for studying parental socialization styles in Portuguese adolescents.

Keywords: Parental socialization styles, ESPA-29, adolescence, validation study.
\end{abstract}

Os estilos parentais podem ser definidos como um conjunto de padrões de comportamento dos pais com os filhos em diversas situações, e têm importantes consequências para a relação paterno-filial. Estes estilos, que começaram a ser estudados empiricamente desde meados do século $\mathrm{XX}$, são um determinante fundamental da comunicação e da conduta na família, influenciam a interiorização de normas, a aquisição de competências e a adaptação social das crianças e adolescentes (García \& Gracia, 2009, 2010; Lamborn, Mounts, Steinberg, \& Dornbusch, 1991; Martínez \& García, 2008; Musitu \& García, 2005; Oliva $\&$ Parra, 2004; Steinberg, 2000).

\footnotetext{
"Endereço para correspondência: Universidade do Algarve, Departamento de Psicologia e Ciências da Educação, Campus de Gambelas, 8005-139 Faro. Portugal 00 351919813927. E-mail: csnunes@ualg.pt, karina.fluis@ gmail.com, ilemos@ualg.pt e gmusoch@upo.es Agradecimentos: Este estudo foi parcialmente financiado pela Fundação para a Ciência e a Tecnologia.
}

Musitu e García (2001, 2004) desenvolveram um modelo relacional a partir das perceções dos adolescentes sobre o comportamento dos pais com duas grandes dimensões: a aceitação/implicação e a coerção/imposição. A aceitação/implicação pressupõe que os comportamentos do filho ajustados às normas de funcionamento familiar sejam reconhecidos pelos pais com manifestações de aprovação. Nesta dimensão são positivas as manifestações parentais de afeto e carinho em resposta aos comportamentos ajustados do filho e negativas as de indiferença. De acordo com este modelo, as práticas parentais associadas a esta dimensão são o afeto, a indiferença, o diálogo e a displicência, que descrevemos de seguida:

$\mathrm{O}$ afeto refere-se ao grau em que o pai/mãe expressam carinho ao filho quando este se comporta corretamente. A indiferença refere-se ao grau em que o pai/mãe não reforçam os comportamentos corretos do filho, permanecendo inexpressivos e insensíveis. O diálogo refere-se ao grau em que o pai/mãe recorrem a uma comunicação bidirecional 
quando não consideram adequado o comportamento do filho. A displicência refere-se ao grau em que o pai/mãe reconhecem os comportamentos não adequados do filho, mas não estabelecem de forma consciente e deliberada o diálogo ou a comunicação com este. De salientar que esta dimensão é na realidade constituída por dois extremos inversamente relacionados de uma mesma dimensão, expressando-se num continuum implicação-aceitação (Musitu \& García, 2001, 2004, 2005).

A coerção/imposição é uma dimensão de socialização parental utilizada para suprimir os comportamentos dos filhos discrepantes com as normas familiares e consiste na privação, coerção verbal e coerção física: A privação refere-se ao grau em que os pais privam o filho de uma vivência gratificante ou the retiram um objeto para corrigir comportamentos inadequados. A coerção verbal refere-se ao grau em que o pai ou mãe repreendem o filho quando este se comporta de maneira incorreta. A coerção física refere-se ao grau em que os pais castigam fisicamente quando este se comporta de maneira incorreta.

Musitu e García $(2001,2004)$ consideram que as dimensões aceitação/implicação e coerção/imposição são independentes e da sua combinação resulta uma tipologia de quatro estilos de socialização parental: Autoritativo, indulgente, autoritário e negligente.

O estilo autoritativo caracteriza-se por níveis elevados de aceitação/implicação e de coerção/imposição. Os pais dirigem as atividades do filho de forma racional incentivando o diálogo e a comunicação, partilham o raciocínio subjacente às normas familiares e exigem o seu cumprimento. Assim, exercem um controle firme do comportamento dos filhos mas têm em conta os seus interesses e direitos. Em caso de divergências dão-lhes espaço para expressarem a sua opinião e utilizam pouco a punição.

O estilo indulgente caracteriza-se por um nível elevado de aceitação/implicação e baixo de coerção/imposição. Estes pais aceitam os impulsos, desejos e comportamentos dos filhos. Consultam os filhos sobre as decisões familiares e explicam-lhes o raciocínio subjacente às regras, mas não os obrigam a cumpri-las, e evitam castigar e coagir. Consideram que os filhos são capazes de regular o seu próprio comportamento.

O estilo autoritário caracteriza-se por um nível baixo de aceitação/implicação e alto de coerção/imposição. São pais muito exigentes e pouco atentos e sensíveis aos interesses, desejos e opiniões dos filhos. Não os incentivam a expressar-se e a comunicação é geralmente unilateral e reprobatória. Assim, estes pais tentam modelar e controlar o comportamento e atitudes do filho, valorizam principalmente a obediência e recorrem à força e à punição quando consideram inaceitável o seu comportamento.

$\mathrm{O}$ estilo negligente caracteriza-se por níveis baixos tanto de aceitação/implicação como de coerção/imposição, ou seja, existe falta de supervisão, controle e cuidados aos filhos. Os pais negligentes geralmente permitem que os filhos cuidem de si mesmos e definam as suas próprias regras. Responsabilizam-nos pela satisfação das suas necessidades físicas e psicológicas e atribuem-lhes uma independência afetiva e material elevada. Estes pais questionam pouco os filhos sobre as decisões e regras familiares, não as explicam nem lhes exigem o seu cumprimento, razão pela qual reagem com indiferença, quer os filhos se comportem de acordo com as regras, quer as transgridam.

Embora existam mais de 90 instrumentos sobre estilos de socialização parental e práticas parentais elaborados desde os anos 30, só dois estão validados para a população portuguesa e só para faixas etárias muito reduzidas. $\mathrm{O}$ EMBU-C (Canavarro \& Pereira, 2007) foi validado com uma amostra de 456 crianças com idades compreendidas entre os 8 e os 11 anos e o Questionário de Estilos Educativos Parentais (Cruz et al., 2011) com 423 adolescentes entre os 12 e 15 anos de idade.

Considerámos útil traduzir e validar para o português o ESPA-29 porque permite estudar os estilos de socialização parental em crianças e adolescentes dos 10 aos 18 anos, contextualiza as pautas de comportamento dos pais em situações cotidianas e foi criado num contexto sociocultural similar ao português. É também de salientar que a sua estrutura fatorial foi replicada por vários estudos realizados em Espanha (López-Jáuregui \& Elosua, 2009) e no Brasil (Martínez, García, Camino, \& Camino, 2011; Martínez, García, Musitu, \& Yubero, 2012). A ESPA-29 tem sido amplamente utilizada em Espanha, no Brasil e em Portugal para estudar o efeito dos estilos de socialização parental, tendo-se observado que se relacionam com o autoconceito dos filhos (Martínez \& García, 2008; Martínez, García, \& Yubero, 2007; Rodrigues, Veiga, Fuentes, \& García, 2013), com os seus valores (Moraes, Camino, da Costa, Camino, \& Cruz, 2007), com a sua adaptação psicológica e com seus os problemas de comportamento (García \& Gracia, 2009, 2010).

O objetivo deste estudo é descrever as propriedades psicométricas da versão portuguesa da escala de estilos de socialização parental na adolescência (ESPA-29) de Musitu e García (2001, 2004).

\section{Método}

\section{Participantes}

Participaram 849 crianças e adolescentes de nove escolas públicas do sul de Portugal, dos quais 363 (42,8\%) eram do sexo masculino e $486(57,2 \%)$ do sexo feminino, com idades compreendidas entre os 10 e os 18 anos $(M=$ $14,57, D P=2,43$; Tabela 1). A maioria dos participantes $(59,13 \%)$ frequentava o ensino básico e $40,87 \%$ o ensino secundário.

\section{Instrumentos}

A Escala de Estilos de Socialização Parental na Adolescência (ESPA-29), desenvolvida por Musitu e García (2001) avalia os estilos de socialização de ambos os pais, a partir de duas dimensões: a Aceitação/Implicação e a Coerção/Imposição que incluem suas subescalas: Afeto, Indiferença, Diálogo, Displicência, Coerção verbal, Coer- 
Nunes, C., Luís, K., Lemos, I. \& Ochoa, G. M. (2015). Características Psicométricas da Versão Portuguesa da Escala de Socialização Parental na Adolescência ESPA-29.

Tabela 1

Distribuição da Idade e Sexo dos Participantes

Sexo

\begin{tabular}{cccccc}
\hline \multicolumn{2}{r}{ Raparigas $(n=486)$} & \multicolumn{2}{c}{ Rapazes $(n=363)$} & Total & $(n=849)$ \\
\hline$n$ & $(\%)$ & $n$ & $(\%)$ & $n$ & $(\%)$ \\
\hline
\end{tabular}

Idade $(M=14,57 ; D P=2,43)$

$\begin{array}{lllllll}10 & 25 & 5,14 \% & 14 & 3,86 \% & 39 & 4,59 \% \\ 11 & 42 & 8,64 \% & 31 & 8,54 \% & 73 & 8,60 \% \\ 12 & 54 & 11,11 \% & 54 & 14,88 \% & 108 & 12,72 \% \\ 13 & 46 & 9,47 \% & 37 & 10,19 \% & 83 & 9,78 \% \\ 14 & 46 & 9,47 \% & 36 & 9,92 \% & 82 & 9,66 \% \\ 15 & 72 & 14,81 \% & 51 & 14,05 \% & 123 & 14,49 \% \\ 16 & 53 & 10,91 \% & 44 & 12,12 \% & 97 & 11,43 \% \\ 17 & 80 & 16,46 \% & 53 & 14,60 \% & 133 & 15,67 \% \\ 18 & 68 & 13,99 \% & 43 & 11,85 \% & 111 & 13,07 \%\end{array}$

Idade Agrupada

$\begin{array}{lllllll}10-14 \text { Anos } & 213 & 43,83 \% & 172 & 47,38 \% & 385 & 45,35 \% \\ 15-18 \text { Anos } & 273 & 56,17 \% & 191 & 52,62 \% & 464 & 54,65 \%\end{array}$

ção Física e Privação. Das 29 situações apresentadas, 16 são negativas (em desacordo com as normas da família, ex.: "se estrago ou parto alguma coisa da minha casa..."), e 13 positivas (ex.: "se respeito e cumpro os horários estabelecidos na minha casa..."), as quais correspondem às situações conformes às regras familiares.

Nas situações positivas são analisados o grau de afeto ("mostra-me carinho") e indiferença ("mostra-se indiferente") da dimensão de Aceitação/Implicação. Nas situações negativas são analisados o diálogo ("fala comigo") e a displicência ("não liga") da dimensão Aceitação/ Implicação e a coerção verbal ("discute comigo"), a coerção física ("bate-me") e a privação ("proíbe-me de...") da dimensão Coerção/Imposição.

Para estimar a frequência percebida de cada comportamento parental os participantes devem avaliar 106 possibilidades de resposta para o pai e a mãe, numa escala de 4 pontos $(1=$ nunca, $2=$ algumas vezes, $3=$ muitas vezes $4=$ sempre) .

\section{Procedimentos}

Depois de obtermos a autorização dos autores para a tradução e utilização da ESPA-29, dois investigadores traduziram independentemente a escala do espanhol ao português.

Posteriormente, a retroversão foi realizada por um terceiro investigador e comparada com a versão original. As inconsistências foram analisadas e corrigidas por consenso. Realizámos um pré-teste com um grupo de 10 adolescentes com idades compreendidas entre os 15 e os 18 anos para identificar eventuais dificuldades de compreensão, não tendo sido necessário realizar alterações.

Após a obtenção das autorizações da Direção Geral de Inovação e de Desenvolvimento Curricular (DGIDC) e dos Conselhos Executivos das escolas, foram obtidos os consentimentos informados dos participantes e dos pais. Os questionários foram aplicados coletivamente, em sala de aula, na presença do investigador. O tempo médio de aplicação dos questionários foi de 30 minutos.

\section{Análises Estatísticas}

As características psicométricas do instrumento foram analisadas através do estudo da sua fidelidade e validade de constructo. A consistência interna foi medida pelo alfa de Cronbach e a estabilidade temporal pelo método de teste-reteste. A validade de constructo foi estudada pela 
análise fatorial exploratória das escalas através do método de componentes principais com rotação ortogonal (VARIMAX), a normalização de Kaiser-Meyer-Olkin (KMO) e com o teste de esfericidade de Bartlett (Carretero-Dios \& Pérez, 2005; Tabachnick \& Fidell, 2007).

Para analisar a estabilidade temporal da ESPA-29, realizámos um reteste a 68 adolescentes, 34 rapazes e 34 raparigas, com idades compreendidas entre os 17 e 18 anos de idade $(M=17,58 ; D P=0,50), 6$ semanas após a aplicação inicial.

O tratamento estatístico dos dados foram realizados com o Statistical Package for Social Sciences (SPSS) v. 18 .

\section{Resultados}

\section{Consistência Interna}

Todas as subescalas apresentaram níveis elevados de consistência interna $(0,88$ a 0,93$)$. A análise de todos os itens do instrumento apresenta uma consistência interna muito boa ( $\alpha=0,95$; Tabela 2$)$. Para analisar a homogeneidade entre os itens e a representatividade de cada subescala com o total da mesma calculámos a mediana das correlações entre os itens e o total de cada subescala. Como podemos observar na Tabela 2 , as subescalas apresentam correlações medianas de magnitude baixa ou moderada, sendo as mais baixas as da indiferença da mãe $(0,02)$ e o afeto do pai $(0,03)$. As correlações item-total mais elevadas foram as de privação do pai $(0,54)$ e da mãe $(0,51)$.

Tabela 2

Estatísticas Descritivas e Consistência Interna das Escalas da ESPA-29

\begin{tabular}{|c|c|c|c|c|c|}
\hline & Subescala & $M$ & $D P$ & $\alpha$ & $M d n r_{i}$ \\
\hline \multirow{7}{*}{$\begin{array}{l}\text { Mãe } \\
n=752 \\
(\alpha=0,91)\end{array}$} & Afeto & 2,96 & 0,74 & 0,91 & $-0,08$ \\
\hline & Indiferença & 1,65 & 0,63 & 0,89 & 0,02 \\
\hline & Diálogo & 2,75 & 0,69 & 0,90 & 0,10 \\
\hline & Displicência & 1,48 & 0,53 & 0,88 & 0,17 \\
\hline & Coerção verbal & 1,86 & 0,67 & 0,91 & 0,39 \\
\hline & Coerção física & 1,16 & 0,38 & 0,93 & 0,46 \\
\hline & Privação & 1,59 & 0,56 & 0,90 & 0,51 \\
\hline \multirow{7}{*}{$\begin{array}{l}\text { Pai } \\
n=752 \\
(\alpha=0,92)\end{array}$} & Afeto & 2,70 & 0,83 & 0,93 & $-0,03$ \\
\hline & Indiferença & 1,79 & 0,72 & 0,90 & 0,12 \\
\hline & Diálogo & 2,50 & 0,73 & 0,91 & $-0,05$ \\
\hline & Displicência & 1,57 & 0,57 & 0,88 & 0,12 \\
\hline & Coerção verbal & 1,79 & 0,64 & 0,91 & 0,43 \\
\hline & Coerção física & 1,17 & 0,39 & 0,93 & 0,49 \\
\hline & Privação & 1,55 & 0,55 & 0,90 & 0,54 \\
\hline$\alpha$ & & & & 0,95 & \\
\hline
\end{tabular}

Nota $. M=$ Média, $D P=$ Desvio Padrão, $\alpha=$ Alfa de Cronbach, $M d n r_{i t}=$ Correlação item-total média da subescala.

\section{Estabilidade Temporal}

As correlações de Pearson entre os dois momentos de aplicação da escala são indicativas de uma boa estabilidade temporal num intervalo de tempo de 6 semanas (Tabela 3). Em todas as subescalas obtivemos correlações de Pearson estatisticamente significativas, exceto na subescala Coerção Física da mãe $(r=-0,06, p=0,629)$. Na comparação das médias obtidas nos dois momentos de aplicação, não observamos diferenças estatisticamente significativas na maioria das subescalas. No entanto a média da subescala
Diálogo referente ao pai aumentou do primeiro $(M=2,52$, $D P=0,67)$ para o segundo momento $(M=2,65, D P=$ $0,75 ; t=-2,05, g l=60, p=0,045)$, apesar da magnitude da diferença ser reduzida $(d=-0,18)$.

\section{Analise Fatorial}

Com base no resultado obtido no teste de esfericidade de Bartlett $(X 2=7326,43, p<0,05, g l=91)$, consideramos pertinente proceder à análise da estrutura fatorial da escala final, onde após a rotação VARIMAX, 
Nunes, C., Luís, K., Lemos, I. \& Ochoa, G. M. (2015). Características Psicométricas da Versão Portuguesa da Escala de Socialização Parental na Adolescência ESPA-29.

Tabela 3

Estabilidade Temporal das Escalas da ESPA-29

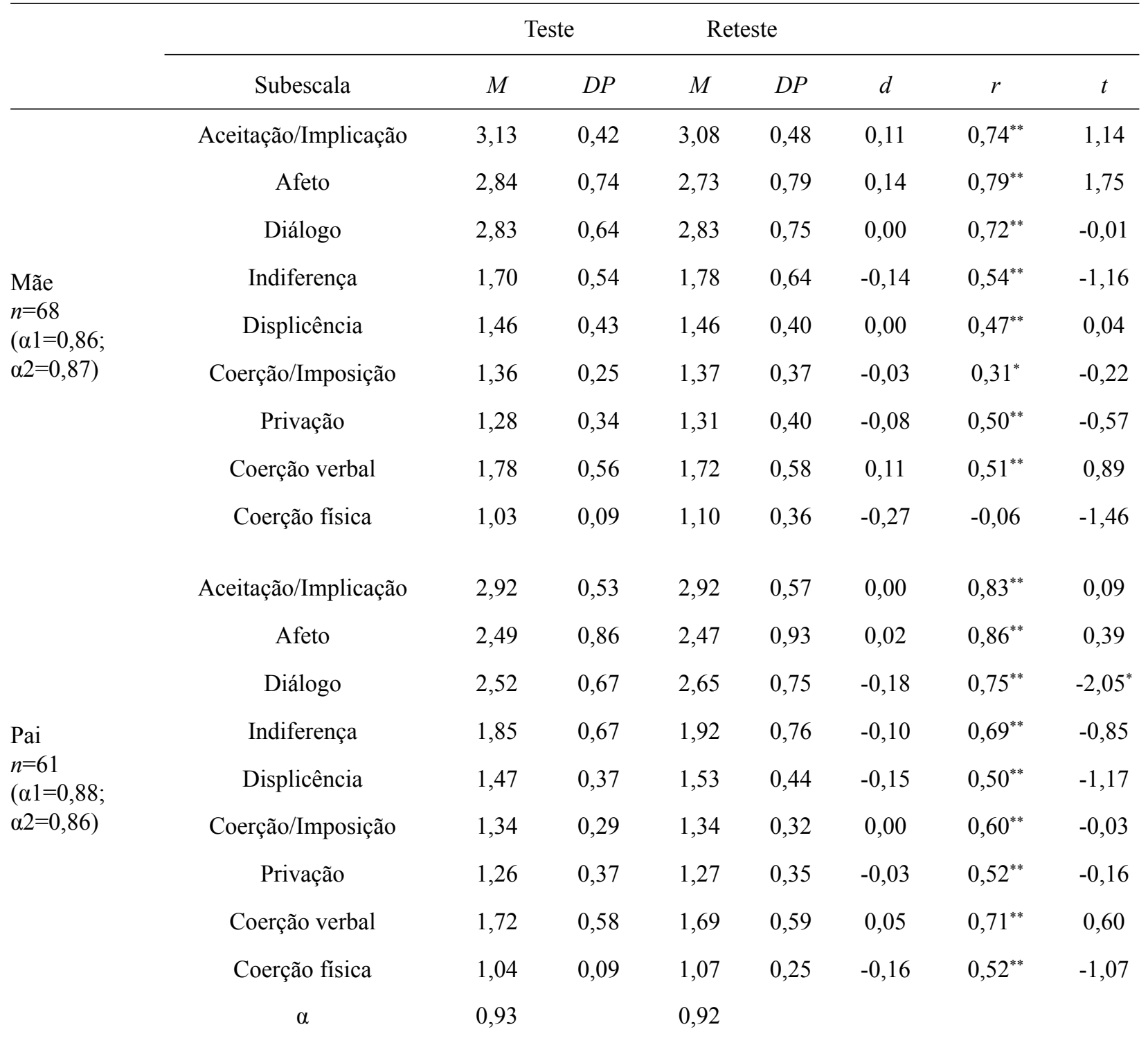

Nota. $M=$ Média, $D P=$ Desvio Padrão, $\alpha=$ alfa de Cronbach, $d=d$ de Cohen, $r=$ Correlação de Pearson entre os dois momentos de teste, $t=$ Teste $t$ de Student para amostras emparelhadas.

$* p \leq, 05 ; * * \leq, 001$.

obtivemos dois fatores que explicam cerca de $54,84 \%$ da sua variância total (Tabela 4). Salientamos também que a medida Kaiser-Meyer-Olkin (KMO) obteve o valor de 0,61 , o que indica uma razoável adequação à amostra (Pereira, 2006).

O fator 1, que corresponde à dimensão Coerção/ Imposição, explicou cerca de $31 \%$ da variância total da escala e agrupou as subescalas referentes à Coerção Verbal e Física e à Privação. Este fator apresentou uma consistência interna elevada $(\alpha=0,97)$, bem como uma saturação positiva com as subescalas Coerção Verbal (0,70 na mãe e 0,73 no pai), Coerção Física $(0,77$ na mãe e 0,77 no pai) e privação (mãe: 0,81 e pai: 0,81 ). A subescala que melhor representa este fator é a Privação, pois apresentou uma saturação positiva mais elevada em ambos os pais, sendo a Coerção Verbal a que obteve índices de saturação menores.

O fator 2 é constituído pelas subescalas Afeto, Indiferença, Diálogo e Displicência, que equivale à primeira dimensão (Aceitação/Implicação) do modelo bidimensional proposto por Musitu e García (2001, 2004). Este fator explicou $23,79 \%$ da variância total do instrumento e apresentou uma consistência interna muito elevada $(\alpha=0,96)$. A subescala que melhor representa este fator é o Afeto, pois manifestou, em ambos os pais, uma saturação positiva mais elevada nas situações positivas $(0,77$ na mãe e 0,83 no pai) e o Diálogo nas situações negativas (mãe: 0,63 , pai: 0,73 ). Esta dimensão saturou negativamente com 
Tabela 4

Saturações Fatoriais, Comunalidades e Consistência Interna das Subescalas de Socialização dos Dois Pais

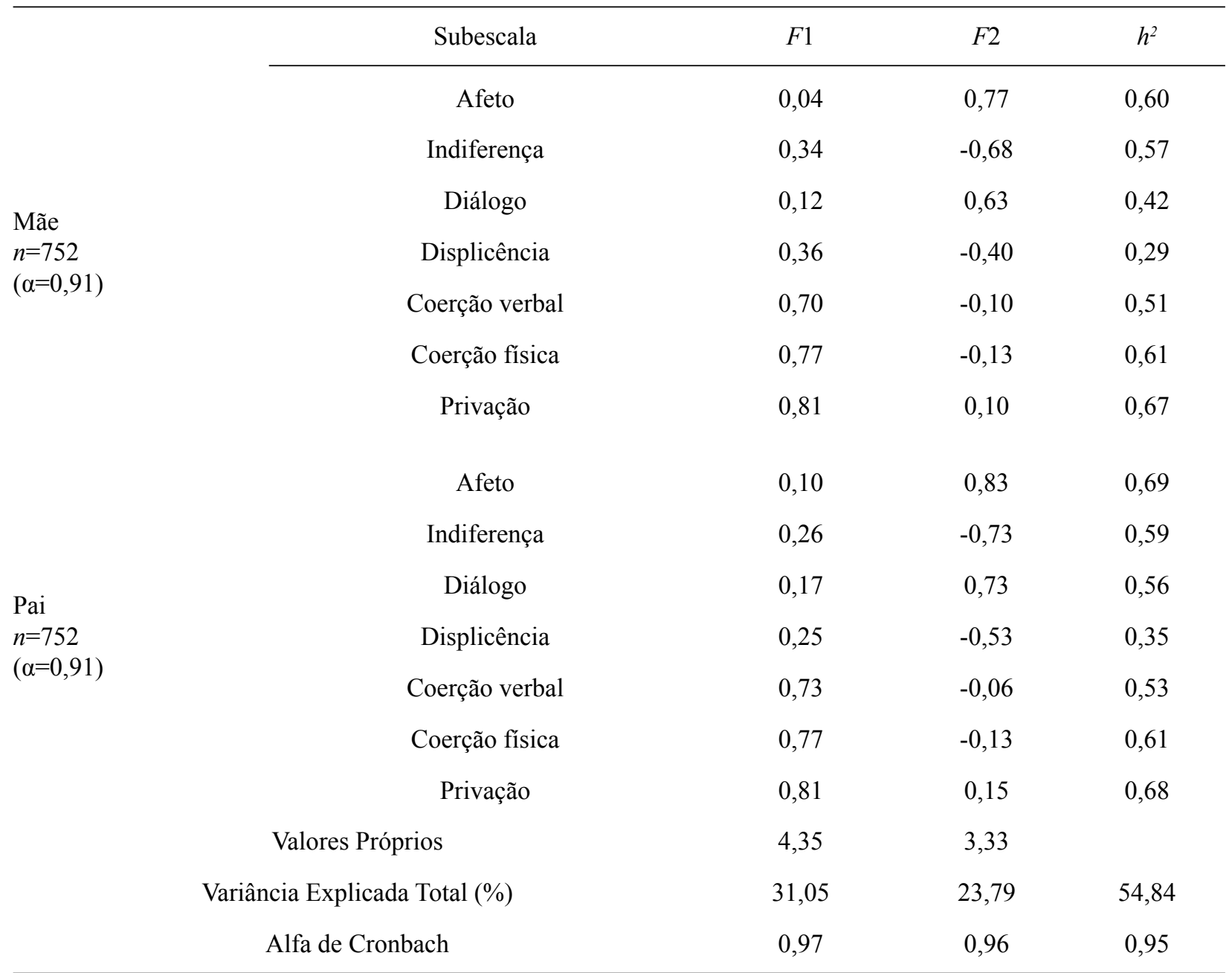

Nota. Saturação fatorial da ESPA-29 (Método: Análise de Componentes Principais, com Rotação VARIMAX, limitada a 2 dimensões), $h^{2}=$ Comunalidades - Estimativa da variância comum a cada item.

a Indiferença em situações positivas (-0,68 na mãe; $-0,73$ no pai), e com a displicência nas negativas (mãe: $-0,40$; pai: $-0,53$; Tabela 4 ).

A análise das comunalidades revela que esta estrutura de dois fatores explica uma parte significativa das subescalas da ESPA-29 (superior a $0,40=40 \%$ ), exceto na prática da Displicência, tanto na mãe $\left(h^{2}=0,29\right)$, como no pai $\left(h^{2}=0,35\right)$.

\section{Discussão}

De uma forma geral, todas as subescalas possuem níveis elevados de consistência interna. Foram encontrados índices mais elevados de consistência interna na subescala Coerção Física para ambos os pais $(\alpha=0,93)$ e mais baixos na subescala Displicência em situações negativas, quer na mãe $(\alpha=0,88)$, quer no pai $(\alpha=0,88)$. Encontrámos ainda valores muito satisfatórios de consistência interna na subescala Afeto do pai $(\alpha=0,93)$, bem como na homogeneidade das subescalas Afeto e Coerção Verbal da mãe $(\alpha=0,91)$ e Diálogo e Coerção Verbal do pai $(\alpha=0,91)$. Na investigação de Musitu e García (2001, 2004), as subescalas que apresentaram uma consistência interna mais elevada foram o Afeto de ambos os pais (Mãe: $\alpha=0,94$, Pai: $\alpha=0,94$ ).

A subescala Displicência foi a que apresentou um menor índice de consistência interna para ambos os pais tal como no estudo original (Mãe: $\alpha=0,84$, Pai: $\alpha=0,82$ ).

A análise da estabilidade temporal revelou um nível satisfatório de fidelidade. Não observámos diferenças estatisticamente significativas entre as médias para a maioria das subescalas, à exceção da subescala Diálogo do pai $(t=-2,05, g l=60, p=0,045)$, embora a magnitude da diferença seja reduzida $(d=-0,18)$. Os adolescentes consideraram que o diálogo paterno aumentou do primeiro para o segundo momento de teste, o que pode estar relacionado com a familiaridade com o instrumento (Canavarro \& Pereira, 2007; Steinberg \& Morris, 2001). É de salientar que também Martínez et al. (2011) observaram um pior 
Nunes, C., Luís, K., Lemos, I. \& Ochoa, G. M. (2015). Características Psicométricas da Versão Portuguesa da Escala de Socialização Parental na Adolescência ESPA-29.

índice de congruência na subescala Diálogo na validação brasileira. É de referir ainda que não observámos uma correlação significativa entre o teste e o reteste na subescala de coerção física da mãe. Este resultado pode dever-se ao facto de esta prática ser pouco usada e a sua variabilidade ser muito reduzida.

A análise fatorial de componentes principais com rotação VARIMAX efetuada com as subescalas dos pais em conjunto, indicou que existem dois fatores bem definidos: a Aceitação/Implicação e a Coerção/Imposição, confirmando a estrutura concetual bidimensional do instrumento. Tal como em Musitu e García (2001, 2004), no nosso estudo, as subescalas Indiferença e Displicência encontram-se no pólo negativo da dimensão Aceitação/Implicação e as práticas de Afeto e Diálogo no extremo positivo da mesma.

Podemos concluir que a versão portuguesa da ESPA29 apresenta características psicométricas ao nível da fidelidade bastante satisfatórias, com elevados níveis de consistência interna e boa estabilidade temporal. Também os resultados das análises fatoriais foram consistentes com os da versão original de Musitu e García $(2001,2004)$ e são similares aos encontrados nos estudos de validação da ESPA-29 para o Brasil (Martínez et al., 2011; Martínez et al., 2012).

Estes resultados sugerem-nos que este instrumento é fiável para o estudo de estilos de socialização parental em adolescentes portugueses.

Não podemos deixar de referir como limitações deste estudo o tipo de amostragem intencional e a falta de representatividade geográfica. Em futuras investigações a amostra deveria ser representativa de todo o país, de modo a poder realizar a padronização do instrumento em Portugal.

\section{Referências}

Canavarro, M., \& Pereira, A. (2007). A percepção dos filhos sobre os estilos educativos parentais: A versão portuguesa do EMBU-C. Revista Ibero-Americana de Diagnóstico y Evaluación/Avaliação Psicologica, 24(2), 193-210. Recuperado em http://www.aidep.org/03 ridep/R24/R2410.pdf

Carretero-Dios, H., \& Pérez, C. (2005). Normas para el desarrollo y revisión de estudios instrumentales. International Journal of Clinical and Health Psychology, 5(3), 521-551. Recuperado em http://www.aepc.es/ijchp/articulos_pdf/ijchp-158.pdf

Cruz, O., Raposo, J. V., Ducharne, M. A., Almeida, L. S., Teixeira, C. M., \& Fernandes, H. M. (2011). Questionário de estilos educativos parentais (QEEP): Contributos para a validação factorial da versão portuguesa das parenting scales. Revista Ibero-Americana de Diagnóstico y Evaluación/Avaliação Psicologica, 31(1), 157-176. Recuperado em http://www. aidep.org/03 ridep/R31/R31\%20art8.pdf

García, F., \& Gracia, E. (2009). Is always authoritative the optimum parenting style? Evidence from Spanish families. Adolescence, 44(173), 101-131. Retrieved from http://www. uv.es/garpe/C /A /C A 0037.pdf

García, F., \& Gracia, E. (2010). ¿Qué estilo de socialización parental es el idóneo en España? Un estudio con niños y adolescentes de 10 a 14 años. Infancia y Aprendizaje, 33, 365-384. doi:10.1174/021037010792215118
Lamborn, S. D., Mounts, N. S., Steinberg, L., \& Dornbusch, S. M. (1991). Patterns of competence and adjustment among adolescents from authoritative, authoritarian, indulgent, and neglectful families. Child Development, 62, 1049-1065. doi:10.1111/j.1467-8624.1991.tb01588.x

López-Jáuregui, A., \& Elosua, P. (2009). Adaptation of the ESPA-29 Parental Socialization Styles Scale to the Basque language: Evidence of validity. The Spanish Journal of Psychology, 12(2), 737-745. doi:10.1017/S1138741600002109

Martínez, I., \& García, F. (2008). Internalization of values and self-esteem among Brazilian teenagers from authoritative, indulgent, authoritarian and neglectful homes. Adolescence, 43(169), 13-29. Retrieved from http://www.uv.es/garpe/C_ A /C A 0034.pdf

Martínez, I., García, J. F., Camino, L., \& Camino, C. P. (2011). Socialização parental: Adaptação ao Brasil da escala ESPA-29. Psicologia: Reflexão e Crítica, 24(4), 640-647. doi:10.1590/S0102-79722011000400003

Martínez, I., García, F., Musitu, G., \& Yubero, S. (2012). Family socialization practices: Factor confirmation of the Portuguese version of a scale for their measurement. Revista de Psicodidáctica, 17, 159-178. doi:10.1387/RevPsicodidact.1306

Martínez, I., García, F., \& Yubero, S. (2007). Parenting styles and adolescents' self-esteem in Brazil. Psychological Reports, 100(3), 731-745. doi:10.2466/pr0.100.3.731-745

Moraes, R., Camino, C., da Costa, J. B., Camino, L., \& Cruz, L. (2007). Socialização parental e valores: Um estudo com adolescentes. Psicología: Reflexão e Crítica, 20(1), 167-177. doi:10.1590/S0102-79722007000100021

Musitu, G., \& García, F. (2001). ESPA-29: Escala de estilos de socialización parental en la adolescencia. Madrid, España: TEA.

Musitu, G., \& Garcia, F. (2004). Manual da ESPA-29 - Escala de Estilos de Socialización Parental en la Adolescencia (2. ed.). Madrid, España: TEA.

Musitu, G., \& Garcia, F. (2005). Consecuencias de la socialización parental en la cultura española. Psychology in Spain, 9(1), 34-40. Recuperado em http://www.psicothema.com/ psicothema.asp? $\mathrm{id}=1196$

Oliva, A., \& Parra, A. (2004). Contexto familiar y desarrollo psicológico durante la adolescencia. In E. Arranz (Ed.), Familia y desarrollo psicológico (pp. 96-123), Madrid, España: Pearson Educación.

Pereira, A. (2006). Guia prático de utilização do SPSS. Análise de dados para Ciências Sociais e Psicologia. Lisboa, Portugal: Edições Sílabo.

Rodrigues, Y., Veiga, F., Fuentes, M. C., \& García, F. (2013). Parenting and adolescents' self-esteem: The Portuguese context. Revista de Psicodidáctica, 18(2), 395-416. doi:10.1387/ RevPsicodidact.6842

Steinberg, L. (2000). The family at adolescence: Transition and transformation. Journal of Adolescent Health, 27, 170-178. doi:10.1016/S1054-139X(99)00115-9

Steinberg, L., \& Morris. A. (2001). Adolescent development. Annual Review of Psychology, 52(1), 83-110. doi:10.1146/ annurev.psych.52.1.83

Tabachnick, B. G., \& Fidell, L. S. (2007). Using multivariate statistics $\left(5^{\text {th }}\right.$ ed.). Boston, MA: Pearson Education. 
Anexo

Conteúdos dos Itens da Versão Portuguesa da ESPA-29

1. Se obedeço ao que me manda

2. Se não estudo ou não quero fazer os trabalhos de casa que me mandam da escola

3. Se vem alguém visitar-nos a casa e porto-me bem

4. Se parto ou estrago alguma coisa em casa

5. Se as minhas notas no final do ano forem boas

6. Se ando sujo e mal-arranjado

7. Se tenho um bom comportamento em casa e não interrompo as suas atividades

8. Se fica a saber que parti ou estraguei alguma coisa fora de casa ou de alguém

9. Se tenho alguma negativa nas minhas notas de final de ano

10. Se ao chegar a noite, volto para casa na hora marcada, sem atrasos

11. Se saio de casa para ir a algum sítio, sem pedir autorização a ninguém

12. Se fico levantado até muito tarde, por exemplo a ver televisão

13. Se algum dos meus professores informa que me porto mal nas aulas

14. Se cuido das minhas coisas e ando limpo e asseado

15. Se digo uma mentira e descobrem que menti

16. Se respeito os horários estabelecidos na minha casa

17. Se fico por aí com as minhas amigas e/ou amigos e chego tarde a casa de noite

18. Se arrumo e cuido as coisas na minha casa

19. Se brigo com algum amigo ou com algum dos meus vizinhos

20. Se fico furioso e perco o autocontrolo por algo que me correu mal ou por alguma coisa que não me concederam

21. Quando não como o que me colocam na mesa

22. Se os meus amigos ou qual quer pessoa lhe dizem que sou bom companheiro

23. Se fala com algum dos meus professores e recebe alguma carta da escola a dizer que me porto bem

24. Se estudo o suficiente e faço os trabalhos de casa

25. Se chateio em casa e não deixo que os meus pais vejam as notícias ou o jogo de futebol

26. Se sou desobediente

27. Se como tudo o que me põem na mesa

28. Se não falto nunca à escola e sou sempre pontual

29. Se alguém vem visitar-nos a casa e faço barulho ou chateio 